\title{
CARACTERIZAÇÃO DE PEÇAS DE MADEIRA PRODUZIDAS EM SERRARIA VISANDO O CONTROLE DE QUALIDADE
}

\section{CHARACTERIZATION OF WOOD PIECES PRODUCED IN SAWMILL FOR QUALITY CONTROL}

\author{
Jackson Roberto Eleotério $^{1}$ Lindolfo Storck $^{2}$ Sidinei José Lopes ${ }^{3}$
}

\section{RESUMO}

A precisão das dimensões é uma característica que determina a qualidade de uma peça de madeira. Um estudo, numa serraria localizada em Cachoeira do Sul, RS, foi realizado com o objetivo de quantificar a magnitude da média e da variância das dimensões das peças de madeira produzidas. A largura e a espessura das peças produzidas por quatro tipos de serras foram avaliadas. Duas serras cortam as toras na largura e duas serras cortam na espessura. Foram calculadas as médias, variâncias e os intervalos de confiança para a média e a variância dentro e entre peças das dimensões de largura e espessura. Os resultados mostram que o corte das peças de madeira segue uma distribuição normal sem tendências.

Palavras-chave: Pinus, processamento mecânico, controle de qualidade.

\section{SUMMARY}

The performance of the saw to produce wood pieces can be measured by the precision of the pieces dimensions. An study was carried out in Cachoeira do Sul, RS, to quantify the mean and the variance of the wood pieces produced in a sawmill. The wood pieces produced by four kind of machine were evaluated. Two machine bandsaw with two saws: a twin bandsaw and a double circular saw headriss produce centered cants. The depth of the pieces was determined by two other machines, with multiple circular saw. The average, variances and the confidence interval was calculated to average and within piece variance produced by the four machine and between piece variance. The results show that the sawn wood pieces folow a normal distribution without tendency.

Key word: Pinus spp., mechanical processing, quality control.

1. Acadêmico do Curso de Graduação em Engenharia Florestal. UFSM. 97.119-900. Santa Maria. RS.

2. Engenheiro Agrônomo, Dr., Prof. Titular do Departamento de Fitotecnia. UFSM. 97.119-900. Santa Maria. RS.

3. Engenheiro Agrônomo, M.Sc., Prof. Adjunto do Departamento de Fitotecnia. UFSM. 97.119-900. Santa Maria. RS. 


\section{INTRODUÇÃO}

Dentro da atividade florestal, o setor madeireiro sempre apresentou grande destaque, tanto em número de empresas como em consumo de madeira. Segundo a FAO apud PONCE (1993), a madeira serrada é o item mais importante em termos de volume das indústrias florestais. Aproximadamente $55 \%$ da madeira roliça industrial colhida anualmente no mundo é processada nas serrarias.

A qualidade da madeira pode ser avaliada de duas maneiras, uma pelas suas características naturais (como, propriedades físicas), e outra pela precisão de suas dimensões. A variação dimensional é uma das causas que dificultam a comercialização e conseqüente baixa competitividade da indústria madeireira brasileira (PONCE, 1993).

A variação dimensional das peças serradas influi significativamente no rendimento. Serrarias com maior variação têm rendimentos menores, isto porque, quanto maiores as variações, maiores devem ser os acréscimos nas medidas das peças serradas. A variação mais crítica para o rendimento é a espessura porém, a utilização de equipamentos sem vibrações como os de serras delgadas, possibilita um bom rendimento. PONCE (1992) salienta que as guias são peças fundamentais na precisão das serras de fita e serras circulares. Há um compromisso predominante para reduzir a variação do processo, pois, controlar o processo é o caminho para assegurar a qualidade do produto.

O sistema americano de controle dimensional é baseado na estatística e tem como objetivo a avaliação do comportamento dos vários tipos de serras no que se refere às variações de corte nas peças produzidas. Amostras de peças coletadas das serras têm suas espessuras ou larguras medidas em vários pontos, de 4 a 10 por peça. São calculados os desvio padrão dentro das peças, entre as peças e o desvio padrão total. O desvio padrão dentro das peças avalia o comportamento das lâminas de serra durante o corte, sua estabilidade e variação. O desvio padrão entre peças avalia o comportamento dos dispositivos bitoladores, aqueles que determinam as espessuras ou larguras durante o corte. O desvio padrão total avalia o comportamento geral, determinando as condições do equipamento, e quanto deve ser o acréscimo nas dimensões da peça para que seja aceita pelo consumidor ou para que no beneficiamento tenha suas superfícies aplainadas (PONCE, 1993).

Quando torna-se difícil o controle de certos processos contínuos ou técnicos de produção, a melhor alternativa é utilizar "Gráficos de Controle". Estes gráficos ou fichas têm como função principal a indicação imediata de tendências de desvios da qualidade de um produto dos limites prédeterminados. Além de indicar a ultrapassagem destes limites, as fichas servem, principalmente, para controle de influências responsáveis pela qualidade insatisfatória do produto. Trata-se mais de evitar a ocorrência de baixa qualidade do produto do que a eliminação posterior do mesmo, como no caso da inspeção de produtos por planos de amostragem (NOCK \& RICHTER, 1979).

No presente trabalho foram avaliadas quatro máquinas de serraria, com o objetivo de determinar os limites de controle no processo de corte das peças. Estes limites são a base para tomar-se providências em função da diferença entre o processo atual e o processo desejável e em função do local onde são encontradas as maiores variações. 


\section{MATERIAL E MÉTODOS}

Este trabalho foi realizado na serraria da TODESMADE Indústria de Madeiras e Artefatos Ltda., localizada no município de Cachoeira do Sul, RS. A produção desta serraria gira em torno de $1500 \mathrm{~m}^{3}$ de madeira serrada de Pinus sp. por mês. O processo de desdobro de madeira já é realizado a alguns anos pelas quatro máquinas avaliadas, não estando estas máquinas em fase de regulagem.

Foram avaliadas quatro máquinas caracterizadas abaixo, sendo que duas serras principais realizam o corte das toras no sentido longitudinal onde foi medido a largura de corte, e as outras duas, fazem o desdobro desta peça, nas quais foram medidas as espessuras de corte.

A primeira máquina avaliada foi a serra circular múltipla, da marca Schiffer, modelo SCM.160, série 1990.05, equipada com duas lâminas de $700 \mathrm{~mm}$ de diâmetro e $5,0 \mathrm{~mm}$ de espessura com fio de serra de $6,3 \mathrm{~mm}$ (serra da direita) e 7,0 $\mathrm{mm}$ (serra da esquerda). O corte realizado por esta serra pode ser regulado em 3, 4 e 5 polegadas. Esta máquina é utilizada para toras médias, com diâmetro em torno de $25 \mathrm{~cm}$, realizando o primeiro corte, no sentido longitudinal. Foram medidas as larguras de 25 peças de 2,8m de comprimento, sendo 9 peças de 3", 12 peças de 4" e 4 peças de 5" de largura regulada.

A segunda máquina avaliada foi a serra fita dupla, da marca Turbina, modelo Tandem, fabricada em setembro de 1992, equipada com serra de lâminas de 1,47mm de espessura (BWG 17) com fio de serra em torno de $3,1 \mathrm{~mm}$. O corte realizado por esta serra pode ser regulado em 3,4 e 5 polegadas. Esta máquina é utilizada para toras maiores que $30 \mathrm{~cm}$, realizando o primeiro corte no sentido longitudinal. Foram medidas as larguras de 42 peças de $2,8 \mathrm{~m}$ de comprimento, sendo 23 peças de 4" e 19 peças de 5" de largura regulada.

A terceira máquina avaliada foi a serra circular múltipla da marca Schiffer, modelo SCM.5.350, série 1990.05, equipada com 8 pares de lâminas de $300 \mathrm{~mm}$ de diâmetro e $3,5 \mathrm{~mm}$ de espessura com fio de 3,65mm nas lâminas do eixo superior e 4,10 $\mathrm{mm}$ nas lâminas do eixo inferior. Os cortes realizados por esta máquina são longitudinais e simultâneos, produzindo até 7 peças de uma polegada de espessura. Esta máquina é utilizada para desdobrar as peças formadas pela máquina SCM.160. Foram medidas as espessuras em 5 pontos de cada uma das 74 peças de $2,8 \mathrm{~m}$ de comprimento.

A quarta máquina avaliada foi a serra circular múltipla, da marca Turbina, modelo SCM.2, série 1990.02, equipada com 9 pares de lâminas de $350 \mathrm{~mm}$ de diâmetro e $3,15 \mathrm{~mm}$ de espessura com fio de 4,5mm. Os cortes realizados por esta máquina são longitudinais e simultâneos, produzindo até nove peças de uma polegada de espessura. Esta máquina é utilizada para desdobrar as peças formadas pela serra fita Tandem. Foram medidas as espessuras em 5 pontos de cada uma das 46 peças de 2,8m de comprimento produzidas por esta máquina.

A espessura de corte de cada peça foi obtida de 0,5 em $0,5 \mathrm{~m}$, sendo o primeiro ponto a $0,5 \mathrm{~m}$ do início da peça, totalizando os 5 pontos de medição por peça. Estes pontos estavam alternados a 3 $\mathrm{cm}$ das bordas laterais das peças. As medidas foram realizadas com paquímetro de verniê, com precisão de décimos de milímetro. Junto com cada medida foi anotada a hora da produção da peça para avaliar possíveis tendências de mudança nas médias e/ou nos intervalos de confiança ao longo do tempo, entre uma operação de afiação das serras e outra. 
A análise estatística constou do cálculo das médias, mínimo, máximo, variância e desvio padrão da largura e espessura de corte das peças para cada máquina por classe de largura regulada (3, 4 e 5 polegadas) e, no geral. Foram aplicados testes de Bartlett e de F (STEEL \& TORRIE, 1960) para verificar a homogeneidade das variâncias entre classes e máquinas. Calculou-se os intervalos de confiança para as médias e variâncias dentro e entre peças por classe e/ou no geral. Foi realizado também, a análise de regressão polinomial para a largura e espessura de corte em função do tempo entre uma afiação das serras e outra.

\section{RESULTADOS E DISCUSSÃO}

Os resultados das estatísticas para as máquinas serra circular múltipla SCM.160 e serra fita Tandem para diferentes larguras reguladas estão apresentados na Tabela 1.

Analisando a variância global entre as classes de largura regulada, o teste de homogeneidade das variâncias de Bartlett foi significativo em nível de 0,0168 para a SCM.160 e de 0,0098 para a serra fita Tandem, indicando que a variabilidade é diferente entre as peças de diferentes larguras reguladas. Para a SCM.160, a variância das larguras das peças de 3" foi significativamente menor, pelo teste de $\mathrm{F}$ em 5\% de erro, do que as variâncias das larguras de 4" e 5", as quais não diferiram entre si. Para a serra fita Tandem o teste de F mostrou que a variabilidade das peças de 4" é menor que a variabilidade das peças de 5\%. A homogeneidade das variâncias é um indicador do grau de estabilidade do mecanismo de corte. Neste sentido, observa-se que o primeiro corte longitudinal tem menos estabilidade quando aumenta a espessura de corte. Nas duas máquinas, SCM.160 e Tandem, as larguras medidas foram significativamente superiores as respectivas larguras reguladas das peças. Apenas conhecendo-se a contração da madeira durante a secagem e a espessura a ser aplainada é que poderíamos julgar se estas sobremedidas são exageradas.

Para ambas as máquinas, as larguras de corte reguladas apresentaram os maiores intervalos de confiança da variância entre peças. Este fato sugere algum problema, como folgas no sistema bitolador que determina as larguras durante o corte. Ressalva deve ser feita quanto aos intervalos de confiança para peças com largura regulada de 5", produzidas pela Serra Circular Múltipla SCM.160, que foram muito grandes em relação as demais larguras possivelmente pelo menor número de graus de liberdade.

Comparando-se a variância global da largura de corte entre as máquinas Serra Circular Múltipla SCM.160 e Serra Fita Tandem, pode-se verificar que a serra circular múltipla Schiffer SCM.160 está operando significativamente com mais precisão. A melhoria na qualidade pode ser obtida pela Serra Fita Tandem, que apesar de apresentar grande variabilidade, não deve ser substituída porque tem a vantagem de possuir um pequeno fio de serra, o que resulta em menor perda de madeira.

A análise de regressão não mostrou tendências entre uma afiação e outra, da média apresentar variação, nem dos intervalos de confiança aumentarem ao longo do tempo. Assim, considera-se que o funcionamento dessas máquinas está sob controle (BRAVO, 1995). 
TABELA 1: Número de pontos de medida, médias de larguras obtidas, valor mínimo e máximo observados, variância global, coeficientes de variação e limites superior (LS) e inferior (LI) do intervalo de confiança a 95\% para a média e variância dentro de peças e entre peças, classificados por máquina e por largura regulada.

\begin{tabular}{|c|c|c|c|}
\hline \multirow[t]{2}{*}{ Estatísticas } & \multicolumn{3}{|c|}{ Largura Regulada } \\
\hline & $3 "$ & 4"' & $5 \%$ \\
\hline \multicolumn{4}{|c|}{ Serra Circ. Múltipla SCM.160 } \\
\hline Número & 45 & 60 & 20 \\
\hline Média (mm) & $78,50 * *$ & $104,9^{\prime} * *$ & $132,34 * *$ \\
\hline Mínimo & 77,20 & 103,20 & 129,80 \\
\hline Máximo & 79,90 & 106,20 & 133,20 \\
\hline Variância & $0,261 \mathrm{~A}$ & $0,452 \mathrm{~B}$ & $0,744 \mathrm{~B}$ \\
\hline Coeficiente de Variação (\%) & 0,65 & 0,64 & 0,65 \\
\hline \multicolumn{4}{|l|}{ Intervalos de Confiança: } \\
\hline Média LI & 77,97 & 104,42 & 127,18 \\
\hline LS & 79,02 & 105,55 & 137,28 \\
\hline Variância dentro LI & 0,020 & 0,046 & 0,092 \\
\hline LS & 0,358 & 0,379 & 9,375 \\
\hline Variância entre LI & 0,088 & 0,175 & 0,168 \\
\hline LS & 1,077 & 1,418 & 77,65 \\
\hline \multicolumn{4}{|c|}{ Serra Fita Tandem } \\
\hline Número & - & 115 & 95 \\
\hline Média (mm) & - & $105,82 * *$ & $132,08^{*}$ \\
\hline Mínimo & - & 99,90 & 127,70 \\
\hline Máximo & - & 109,10 & 136,60 \\
\hline Variância & - & $2,283 \mathrm{~A}$ & $3,791 \mathrm{~B}$ \\
\hline Coeficiente de Variação (\%) & - & 1,42 & 1,47 \\
\hline \multicolumn{4}{|l|}{ Intervalos de Confiança: } \\
\hline Média LI & - & 105,05 & 130,86 \\
\hline LS & - & 106,59 & 133,30 \\
\hline Variância dentro LI & - & 0,431 & 0,334 \\
\hline LS & - & 1,823 & 1,657 \\
\hline Variância entre LI & - & 0,931 & 1,765 \\
\hline LS & - & 3,931 & 8,760 \\
\hline
\end{tabular}

* Variâncias não seguidas pela mesma letra, na linha, diferem significativamente pelo teste de $\mathrm{F}$ em 5\% de erro; $* *$ Médias significativamente maiores que a dimensão regulada, pelo teste de $t$ em $5 \%$ de erro.

Pela representação gráfica da distribuição de freqüências das larguras das peças produzidas pela Serra Circular Múltipla (Figura 1) pode-se observar que, para largura regulada em 3" a distribuição é assimétrica para a esquerda com muitos valores acima da média $(78,50 \mathrm{~mm})$, o que representa uma perda de material. Para a largura regulada em 4" a distribuição é aproximadamente simétrica, com alguns pontos extremos para a esquerda, cujas peças estão sub-dimensionadas. 
Serra Circular Múltipla SCM.160 (a)

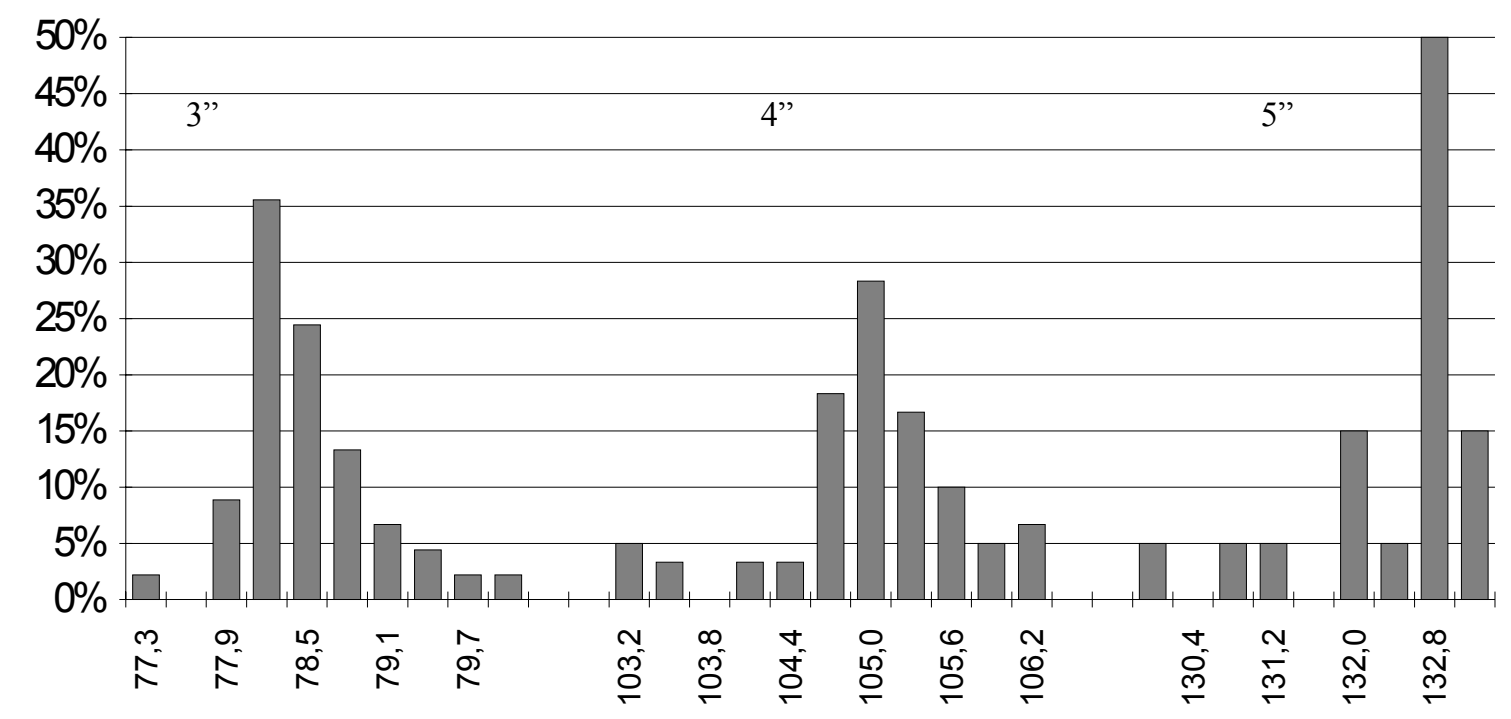

Largura de corte (mm)

Serra Fita Tandem (b)

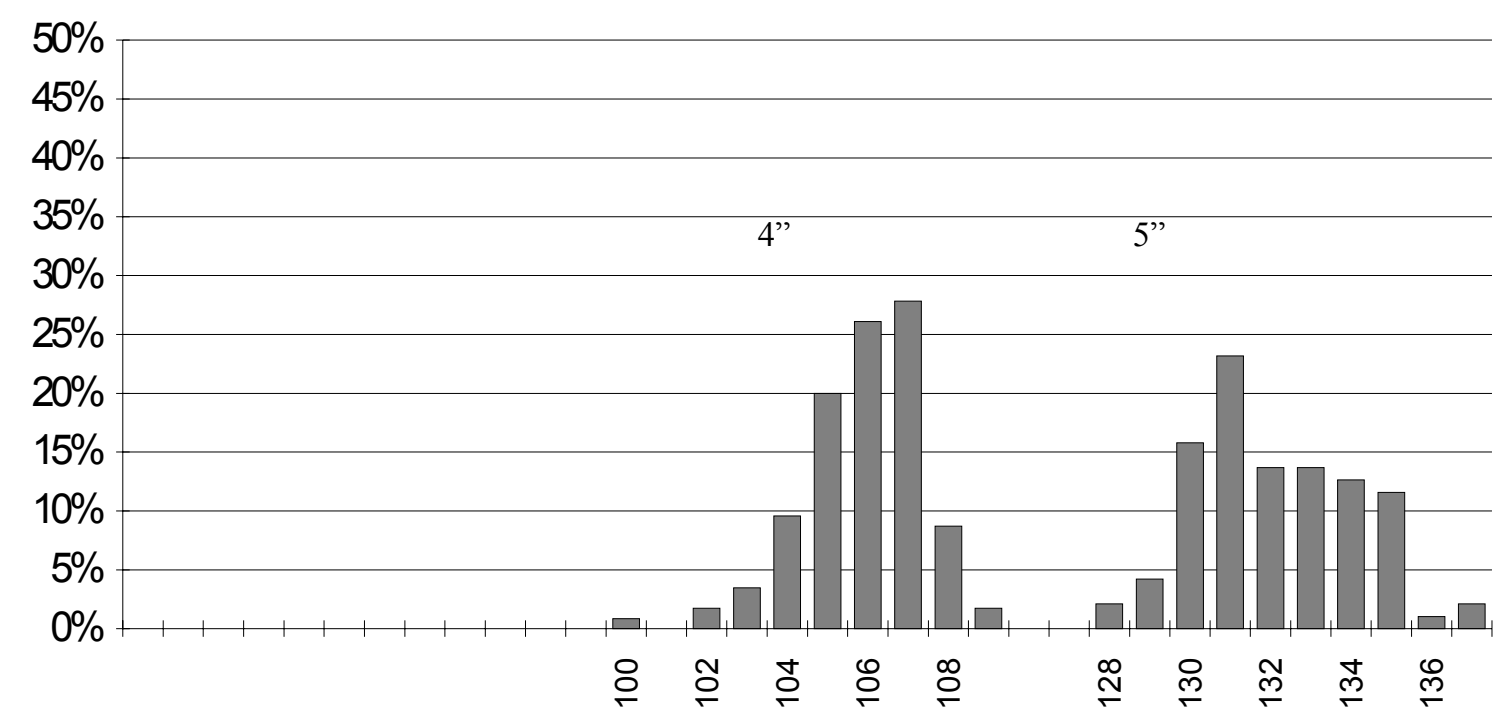

Largura de corte $(\mathrm{mm})$

FIGURA 1: Distribuição de freqüência relativa (\%) das larguras de corte de peças de madeira, para três regulagens de largura (3", 4" e 5"). Máquinas Serra Circular SCM.160 e Serra Fita Tandem.

O mais importante ao analisar a produção dessa máquina é a sobremedida de corte aparentemente superdimensionada, com a variância do processo, a dimensão regulada de peças em 3" $(76,2 \mathrm{~mm})$ teve o corte médio de $78,5 \mathrm{~mm}$; para peças de 4 " $(101,6 \mathrm{~mm})$ teve média de $104,99 \mathrm{~mm}$ 
e para as peças de $5 "(127 \mathrm{~mm})$ teve uma dimensão média de corte de $132,34 \mathrm{~mm}$.

A distribuição de freqüência das larguras das peças produzidas pela Serra Fita Tandem (Figura 1) mostra maior dispersão do que a anterior. Nas peças com largura regulada em 4" existem peças com largura abaixo do valor mínimo. Especialmente para as peças com largura regulada de 5" observa-se o grande problema da maior variância no processo de corte: a exigência de grandes sobremedidas de corte que têm influência direta sobre o rendimento da serraria.

A serra circular múltipla SCM.5.350 e a serra circular múltipla SCM.2 que desdobram as peças produzidas pelas serras principais (SCM.160 e serra fita Tandem, respectivamente) apresentam características de variabilidade heterogênea da espessura das peças cortadas, conforme resultados do teste de Bartlett (Tabela 2), salientando que algum fator age isoladamente sobre cada peça ou par de peças vizinhas.

TABELA 2: Número de ordem da posição na peça, tomada da direita para a esquerda, graus de liberdade $(\mathrm{GL})$, média $(\mathrm{mm})$ e variância $\left(\mathrm{S}^{2}\right)$ para a espessura de peças produzidas por duas máquinas de corte.

\begin{tabular}{c|c|c|c|c|c|c}
\hline \multicolumn{4}{c}{ Serra Circ. Mult. SCM.5.350 } & \multicolumn{3}{c}{ Serra Circ. Mult. SCM.2 } \\
\hline Peça & GL & Média & $\mathrm{S}^{2}$ & GL & Média & $\mathrm{S}^{2}$ \\
\hline 1 & 19 & 27,58 & 0,265 & - & - & - \\
2 & 69 & 27,31 & 0,202 & 29 & 26,94 & 0,085 \\
3 & 94 & 26,94 & 0,097 & 44 & 26,87 & 0,081 \\
4 & 84 & 26,91 & 0,034 & 29 & 26,55 & 0,053 \\
5 & 74 & 26,95 & 0,079 & 44 & 26,90 & 0,024 \\
6 & 24 & 27,58 & 0,109 & 34 & 26,75 & 0,522 \\
7 & - & - & - & 34 & 26,57 & 0,229 \\
\hline Médias & \multicolumn{7}{c}{27,08} & 0,109 & & 26,77 & 0,160 \\
$\chi_{\text {calculado }}^{2}$ & & $72,7 *$ & & & $114,04^{*}$ \\
\hline
\end{tabular}

* variâncias entre peças heterogêneas pelo teste qui-quadrado $\left(\chi^{2}\right)$ de Bartlett em $5 \%$ de erro.

A hipótese mais provável é de que cada serra tenha um comportamento diferenciado, gerando variações diferenciadas entre as peças. Por outro lado, há uma tendência quase geral das peças centrais apresentarem menor variância, fato este que pode ser decorrente da facilidade do corte próximo à medula da madeira (menos densa) ou dos rolos que comandam o avanço e prendem as peças durante o corte atuarem melhor no centro do bloco a ser cortado. Verifica-se que a média da espessura de todas as peças, nas duas máquinas, bem como a média geral são bem superiores à dimensão regulada.

Para ambas as máquinas, a hipótese de que a variabilidade em espessura é proporcional à largura das peças, por peças mais largas trabalharem mais com os dois eixos da serra, foi rejeitada pelo teste de Bartlett (Tabela 3).

Este fato é altamente desejável e significa que estas serras não perdem desempenho quando aumenta a área de corte, o sistema está dimensionado tanto para madeira de menores como as de maiores dimensões. Significa ainda, uma independência entre as máquinas que executam o primeiro corte longitudinal (SCM.160 e serra fita Tandem) e àquelas que fazem o desdobro das 
TABELA 3: Largura regulada, graus de liberdade (GL), médias e variância para a espessura de peças de diferentes máquinas.

\begin{tabular}{c|c|c|c|c|c|c}
\hline \multicolumn{4}{c|}{ Serra Circular Múltipla SCM.5.350 } & \multicolumn{3}{c}{ Serra Circular Múltipla SCM.2 } \\
\hline $\begin{array}{c}\text { Largura } \\
\text { Regulada }\end{array}$ & GL & $\begin{array}{c}\text { Média } \\
(\mathrm{mm})\end{array}$ & Variância & GL & $\begin{array}{c}\text { Média } \\
(\mathrm{mm})\end{array}$ & Variância \\
\hline 3" & 139 & 27,0464 & 0,1794 & - & - & - \\
4" & 199 & 27,1095 & 0,1406 & 119 & 26,7042 & 0,4698 \\
5" & 29 & 27,1867 & 0,2074 & 104 & 26,8371 & 0,3506 \\
\hline Médias & \multicolumn{7}{c}{27,09} & 0,160 & & 26,76 & 0,414 \\
$\chi_{\text {calculado }}^{2}$ & & $3,6^{\mathrm{ns}}$ & & & $2,35^{\mathrm{ns}}$ \\
\hline
\end{tabular}

ns: variâncias entre larguras reguladas não heterogêneas pelo teste de Bartlett.

peças (SCM.5.350 e SCM.2), ou seja, nas serras principais a variância aumenta com a largura de corte, mas isto não afeta os processos seguintes.

Durante o processo de produção foi feita uma limpeza nos bitoladores, removendo restos de resina e realizado a afiação das serras a fim de reduzir a variabilidade da espessura das peças, iniciando-se assim, um segundo ciclo do processo, que comparado com o estado inicial da máquina não apresentou melhoria.

Para a Serra Circular Múltipla SCM.5.350, a distribuição de freqüências das espessuras de corte (Figura 2) é assimétrica à direita, com isso, pode-se tentar reduzir as freqüências de valores muito altos com ganhos no rendimento.

A serra circular múltipla SCM.2 apresenta as freqüências bem agrupadas (Figura 3), simétricas e apenas esporádicos valores extremos.

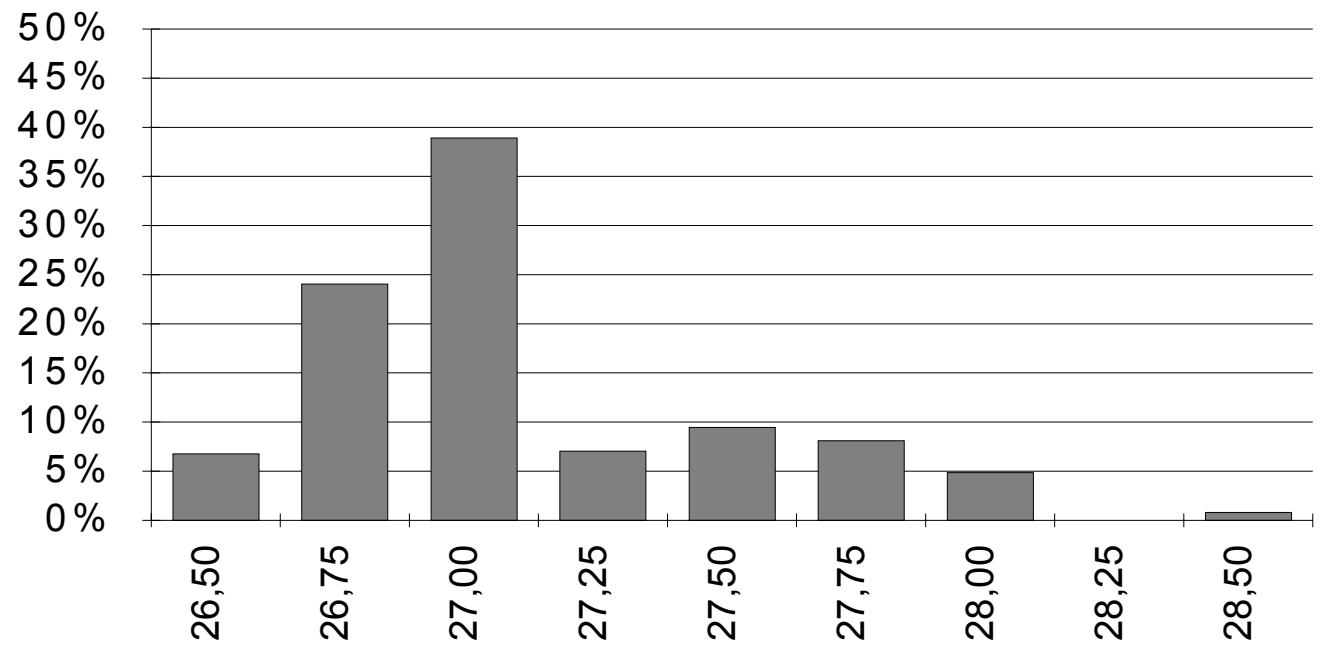

Largura de Corte $(\mathrm{mm})$

FIGURA 2: Distribuição de freqüência relativa (\%) das espessuras de corte de peças de madeira para Máquina Serra Circular Múltipla SCM.5.350. 


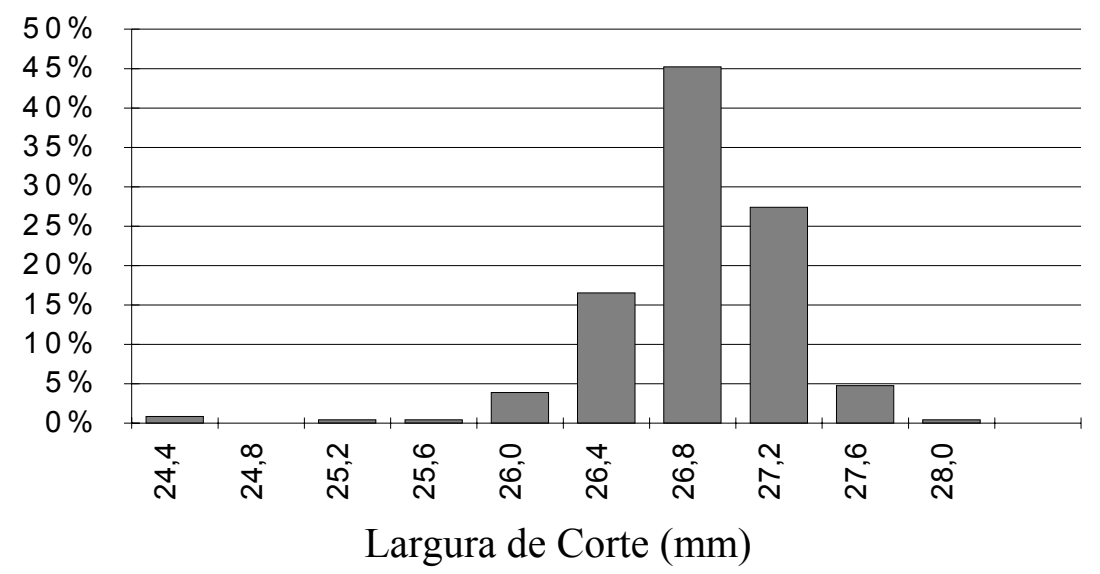

FIGURA 3: Distribuição de freqüência relativa (\%) das espessuras de corte de peças de madeira para Máquina Serra Circular Múltipla SCM.2.

A análise de regressão não mostrou tendências, entre uma afiação e outra, da média apresentar variação, nem dos intervalos de confiança aumentarem ao longo do tempo. Assim, considera-se que o funcionamento dessas máquinas está sob controle (BRAVO, 1995).

A variância global entre as máquinas de desdobro das peças não apresentou diferença significativa pelo teste de $\mathrm{F}$ em $5 \%$ de erro (Tabela 4), ambas trabalham no processo com a mesma variabilidade.

TABELA 4: Número de pontos de medida, médias de espessura obtidas, valor mínimo e máximo observados, variância global, coeficientes de variação e limites superior (LS) e inferior (LI) do intervalo de confiança a 95\% para a média e variância dentro de peças e entre peças, classificados por máquina.

\begin{tabular}{|c|c|c|}
\hline Estatística & $\begin{array}{c}\text { Serra Circ. Múlt. } \\
\text { SCM.5.350 }\end{array}$ & $\begin{array}{c}\text { Serra Circ. Múlt. } \\
\text { SCM.2 }\end{array}$ \\
\hline Número & 370 & 230 \\
\hline Média (mm) & $27,09 a^{*}$ & $26,76 b$ \\
\hline Mínimo & 26,40 & 24,40 \\
\hline Máximo & 28,50 & 27,80 \\
\hline Variância & $0,161 \mathrm{~A}^{*}$ & $0,175 \mathrm{~A}$ \\
\hline Coeficiente de Variação (\%) & 1,48 & 1,56 \\
\hline \multicolumn{3}{|l|}{ Intervalos de confiança: } \\
\hline Média LI & 26,98 & 26,64 \\
\hline LS & 27,20 & 26,89 \\
\hline Variância dentro LI & 0,032 & 0,060 \\
\hline LS & 0,070 & 0,163 \\
\hline Variância entre LI & 0,086 & 0,065 \\
\hline LS & 0,189 & 0,177 \\
\hline
\end{tabular}

* Médias e variâncias não seguidas por mesma letra diferem significativamente pelos respectivos testes de $\mathrm{t}$ e $\mathrm{F}$ em $5 \%$ de erro. 
Analisando os intervalos de confiança da variância dentro e entre peças, pode-se observar que são muito semelhantes, levemente inferior para a variância dentro de peças produzidas pela Serra Circular Múltipla SCM.5.350. A pequena variância entre peças (Tabela 2) pode ser explicada pelo fato da bitola de corte permanecer fixa, não sofrendo regulagens periódicas.

Para um controle de qualidade no processo de corte destas máquinas deve-se considerar que as estatísticas média e variância se mantenham dentro dos limites (LI e LS) estabelecidos nas Tabelas 1 e 4, para as respectivas larguras e espessuras reguladas. Fora disto, as máquinas devem ser desligadas e os defeitos corrigidos.

\section{CONCLUSÕES}

A variância das medidas de largura aumenta com o aumento da área de corte nas serras principais, isto já não ocorre nas serras SCM.5.350 e na SCM.2. A Serra Fita Tandem apresenta uma estabilidade de medidas superior à Serra Circular Múltipla SCM.160, sendo assim, a máquina que necessita mais ajustes para a estabilidade do mecanismo de corte; as Serras Circulares Múltiplas SCM.5.350 e SCM.2 apresentam estabilidade no mecanismo de corte da espessura; e, todo o processo de desdobro permanece estável ao longo do tempo, com isso, ficam definidos os intervalos de controle de médias e variâncias para o acompanhamento da produção e da eficiência de um possível controle de qualidade.

\section{AGRADECIMENTOS}

A TODESMADE Indústria de Madeiras e Artefatos Ltda., localizada no município de Cachoeira do Sul, RS pela colaboração na obtenção dos dados.

\section{REFERÊNCIAS BIBLIOGRÁFICAS}

BRAVO, P.C. Controle Estatístico da Qualidade In: REUNIÃO ANUAL BRASILEIRA DA SOCIEDADE INTERNACIONAL DE BIOMETRIA, 40aㅡㄹ E SIMPÓSIO DE ESTATÍSTICA APLICADA À EXPERIMENTAÇÃO AGRONÔMICA, 6º ${ }^{\circ}$, Ribeirão Preto, 1995. Minicursos. Ribeirão Preto: USP, 1995.

NOCK, H. P., RICHTER, H. G. Tópicos de Tecnologia da Madeira - Controle de Qualidade na Indústria Madeireira. Curitiba: UFPr-Curso de Pós-Graduação em Engenharia Florestal, 1979.

PONCE, R. H. Tecnologia de Desdobro de Pinus e Eucalyptus: a busca da competitividade In: SIMPÓSIO FLORESTAL DO RIO GRANDE DO SUL. Porto Alegre: Ageflor, 1992.

PONCE, R. H. Novas Tecnologias de Desdobro e Beneficiamento de Madeira: a busca da 
competitividade In: ANAIS DO $7^{\mathrm{O}}$ CONGRESSO FLORESTAL BRASILEIRO. Curitiba: SBS e SBEF, 1993. p 310-314.

STEEL, R.G.D., TORRIE, J.H. Principles and procedures of statistics. Nova York: McGraw Hill Book, 1960. 481p. 